\title{
A view from Web of Science: Journals, articles, impact
}

\author{
James Testa \\ Vice President, Emeritus, Editorial Development and Publisher Relations, Thomson Reuters, 1500 \\ Spring Garden Street, Fourth floor, Philadelphia, PA 19130, USA \\ E-mail: james.testa@thomsonreuters.com
}

\begin{abstract}
Scholarly communication is truly global. While in the past, articles based upon scientific research were primarily from the United States and Europe, today countries such as China, South Korea, and Brazil - along with others that were minor contributors a decade or so ago - are becoming major players. Journals of regional importance have emerged that are worthy of consideration. In parallel, a certain level of global competition has also emerged and as a result it has become obvious that some questionable publishing activities such as self-citations and the acceptance of research papers that are shallow in content are now in play. This paper will take a look at the publication activity as noted in Thomson Reuters' Web of Science over the past decade from a set of ten selected countries.

Keywords: Webndia journal rankings, Sa of Science, Regional Journals, global impact factors, Brazil journal rankings, China journal rankings, South Korea journal rankings, India journal rankings, Spain journal rankings, Turkey journal rankings, Poland journal rankings, Australia journal rankings, South Africa journal rankings, Poland journal rankings
\end{abstract}

\section{Introduction}

In this paper I would like to share with you some data related to the coverage in Web of Science of journals and articles from a selected set of the following ten countries (in alphabetical order): Australia, Brazil, China, India, Italy, Poland, S. Africa, S. Korea, Spain, and Turkey. These countries were chosen mainly because of recent changes in their journal coverage in the Web of Science. Each of these countries has had a relatively significant increase in the number of journals covered in Web of Science in recent years. The growth spurt for these countries began between 2005 and 2010 when they each added at least forty journals to their coverage in Web of Science. Most of them have been able to add even more than that. How did this happen?

The Editorial Development team at Thomson Reuters has spent most of the last fifty years laboring to evaluate and select for coverage as many top-tier international journals as possible. Each year we would select from ten percent to twelve percent of the two thousand journals reviewed. Basically we were looking for journals that would be active participants in the exchange of citations and that would enrich the citation network of the various indexes - journals with some measurable citation impact.

The advent of the World Wide Web had, as you all know, a profound effect on the communication of scholarly results in journals. Many journals that were hidden or fairly obscure in print were now revealing themselves to the online world. With the introduction of Web of Science online our relationship with the community of scholarly publishers also began to change. Participation in the global community of scholarly research was now possible on a whole new level. These and other factors helped us understand that it was time to broaden our view of things and to look just beyond at all this new material. 


\section{Citations in the digital world}

As we moved into the 21 st century we saw that our user base had become increasingly globalized and internationally diverse.

We were traveling regularly to China, South Korea and other countries in the Far East and Southern Asia. We were also hosting a steady stream of visitors from these countries in our Philadelphia, PA (USA) office.

The purpose of these travels and visits was invariably to listen to publishers and editors promoting their journals and seeking coverage in Web of Science. The growing numbers of journals from Asia and from countries far distant from the U.S. and U.K. (both geographically and culturally) started to occupy a great deal of our time and resources. Despite their typically low impact on the international literature, it was difficult to justify simply ignoring all these outlying publications or to deny their local importance.

In 2006 we decided to broaden our view of things and to explore seriously and with intent the vast world of Regional Journals. For our purposes in Editorial Development we defined a Regional Journal as a serial publication originating outside the U.S. or U.K. that contains the scholarship of authors from a particular region or country and that covers topics of regional interest or topics studied from a regional perspective. Regional journals may be widely-used by a local population, but rarely have broad international interest and are characteristically low in citation impact, their specific usefulness in the region notwithstanding. We made room for a collection of top-tier Regional Journals in Web of Science and between 2006 and 2009 added around sixteen hundred of them to our coverage.

Figure 1 shows a view from 2004 to 2015. In the years preceding and following the Regional Journal focus you can see how very gradually and slowly coverage normally grows in Web of Science. The years from 2006 to 2009 were remarkably different in this respect. Looking at the whole twelve-year period there are some interesting progressions.

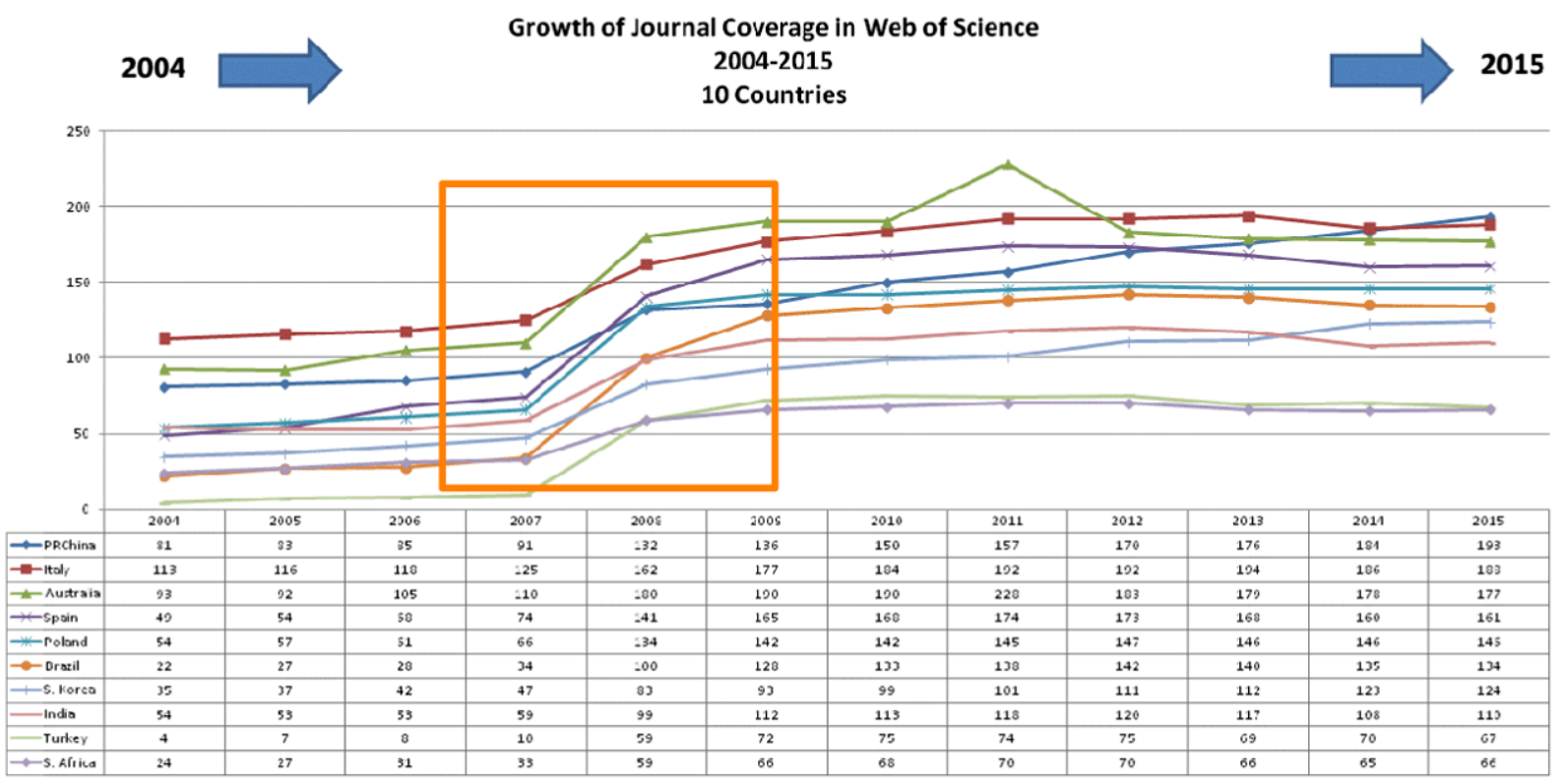

Fig. 1. Growth of journal coverage in web of science 2004-2015. 
In 2004 Italy, Australia and China lead with 113, 93 and 81 covered journals, respectively. By 2015, however, China has taken the lead with one hundred and ninety-three journals followed by Italy with one hundred and eighty-eight and Australia with one hundred and seventy-seven. China, Spain, and Brazil each increased their coverage by one hundred and twelve journals and Turkey went from four journals to sixty-seven.

In Fig. 2 we see the growth of papers year by year over the twelve-year period. In 2004 China lead the others by a modest fifteen thousand papers for the year in Web of Science. By 2015 China had managed to quadruple its annual output from sixty-five thousand articles to nearly two hundred and seventy-five thousand articles. Italy is still in second place in 2015, but now trails China by one hundred and ninetyone thousand articles.

In Fig. 3 we see the countries ranked by total journal coverage in 2015 .

In Fig. 4 we see the total papers per country over the twelve-year period. Italy has only five fewer journals than China in Web of Science but 1.1 million fewer papers. More about that in a moment.

Figure 5 shows the ten countries ranked by normalized citation impact. This is where the differences between quality and quantity are seen clearly. China, which ranked number one in both number of journals and number of papers in Web of Science, now ranks in seventh place by Citation Impact. Were I to have included the U.S., U.K., France, Germany, Japan and other developed countries, its rank would be even lower.

Figure 6 shows a comparative view of the 2015 rankings by number of journals, number of papers and citation impact. Italy has maintained its place in all three measures. Australia and Spain held onto second and third place in journals and papers and Australia moves to first place in Impact. S. Africa moves up to fourth place in Impact and so on. The underlying causes for these changes in rankings could be the subject of lots of studies. There are, however, a few easy observations.

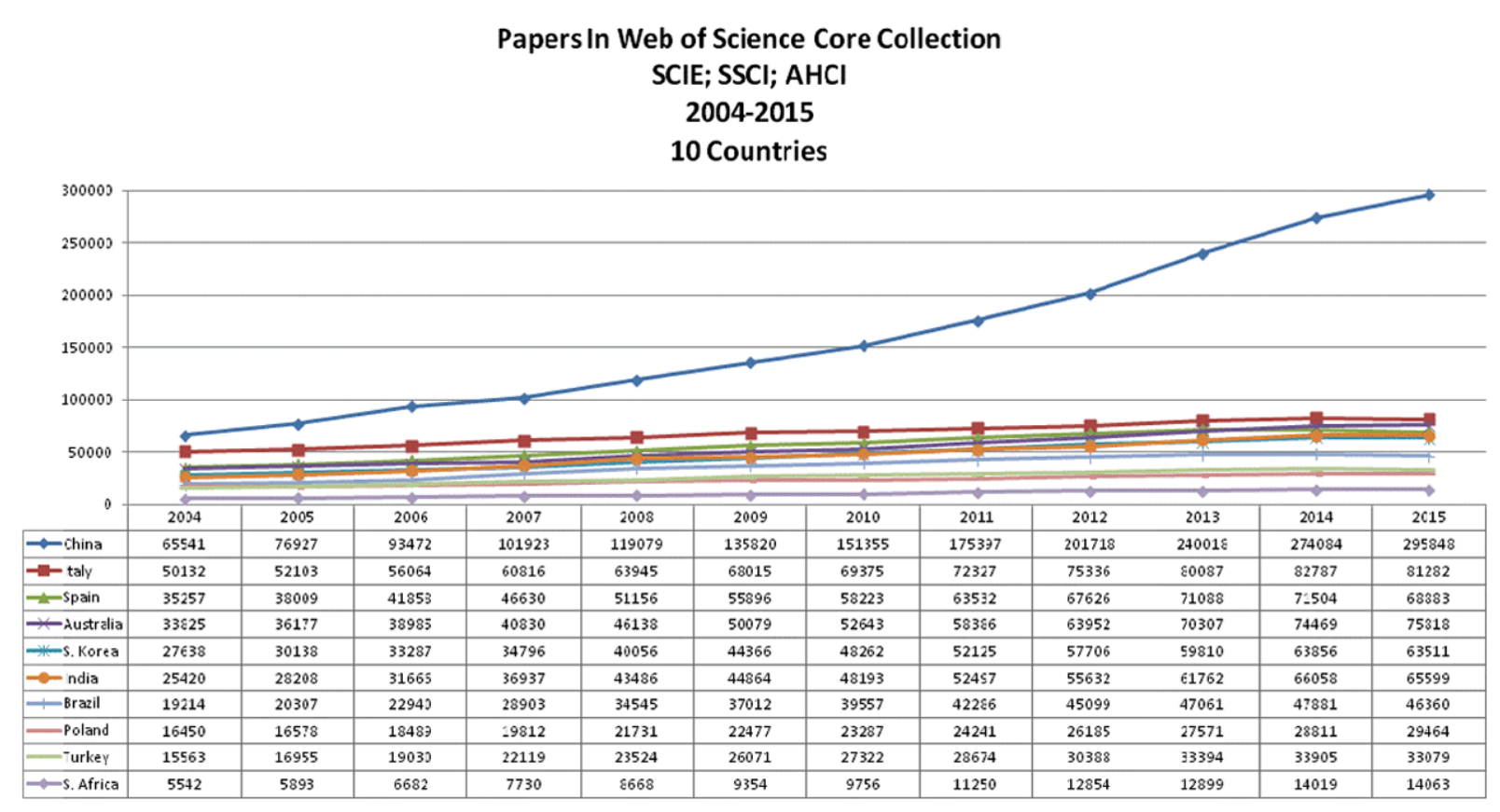

Fig. 2. Papers in web of science core collection (SCIE; SSCI; AHCI) 2004-2015. 


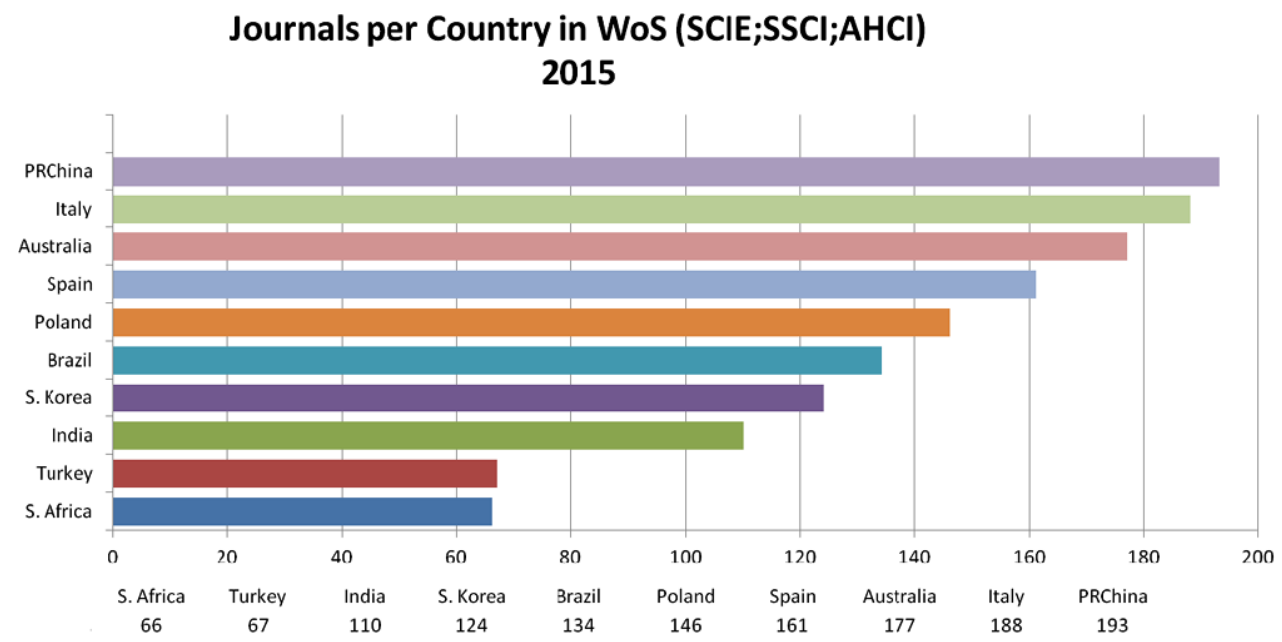

Fig. 3. Journals per country in WoS (SCIE; SSCI; AHCI) 2015.

Total Papers per Country in WoS (SCIE; SSCl; AHCl) 2004-2015

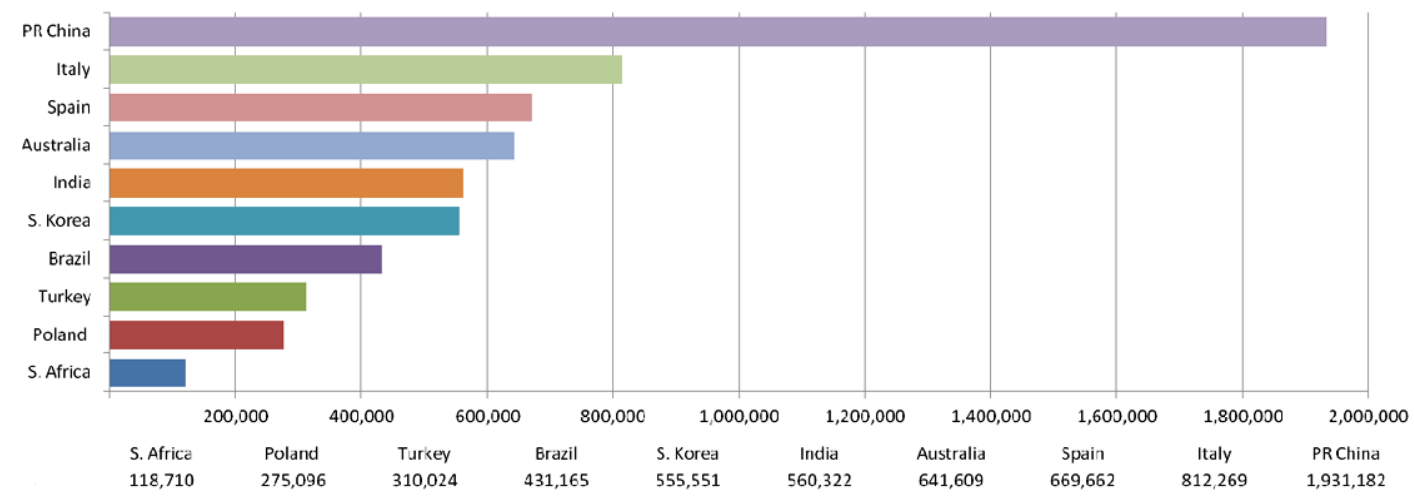

Fig. 4. Total papers per country in WoS (SCIE; SSCI; AHCI) 2004-2015.

The first is that Australia's lead in impact probably has a great deal to do with language and a resulting ability to collaborate and cooperate with the international community. The second is that China's descent to seventh place has a great deal to do with its drive and energy in generating huge numbers of papers, papers that are often characteristically shallow in their level of invention and/or originality, and that are rarely the result of authentic collaborative and cooperative efforts involving the broader international community.

It is also widely-known that the Chinese receive substantial rewards for publishing in journals covered in the Web of Science and are highly motivated thereby. Their drive to publish in Web of Science far outstrips the ability to do so within the fairly narrow scope of the one hundred and ninety-three Chinese journals covered. Indeed I doubt there is a successful publisher anywhere in the world with a presence in Web of Science who is not plagued with a veritable tsunami of papers from China and from other countries that reward publishing based on the impact or placement of the target journal. 


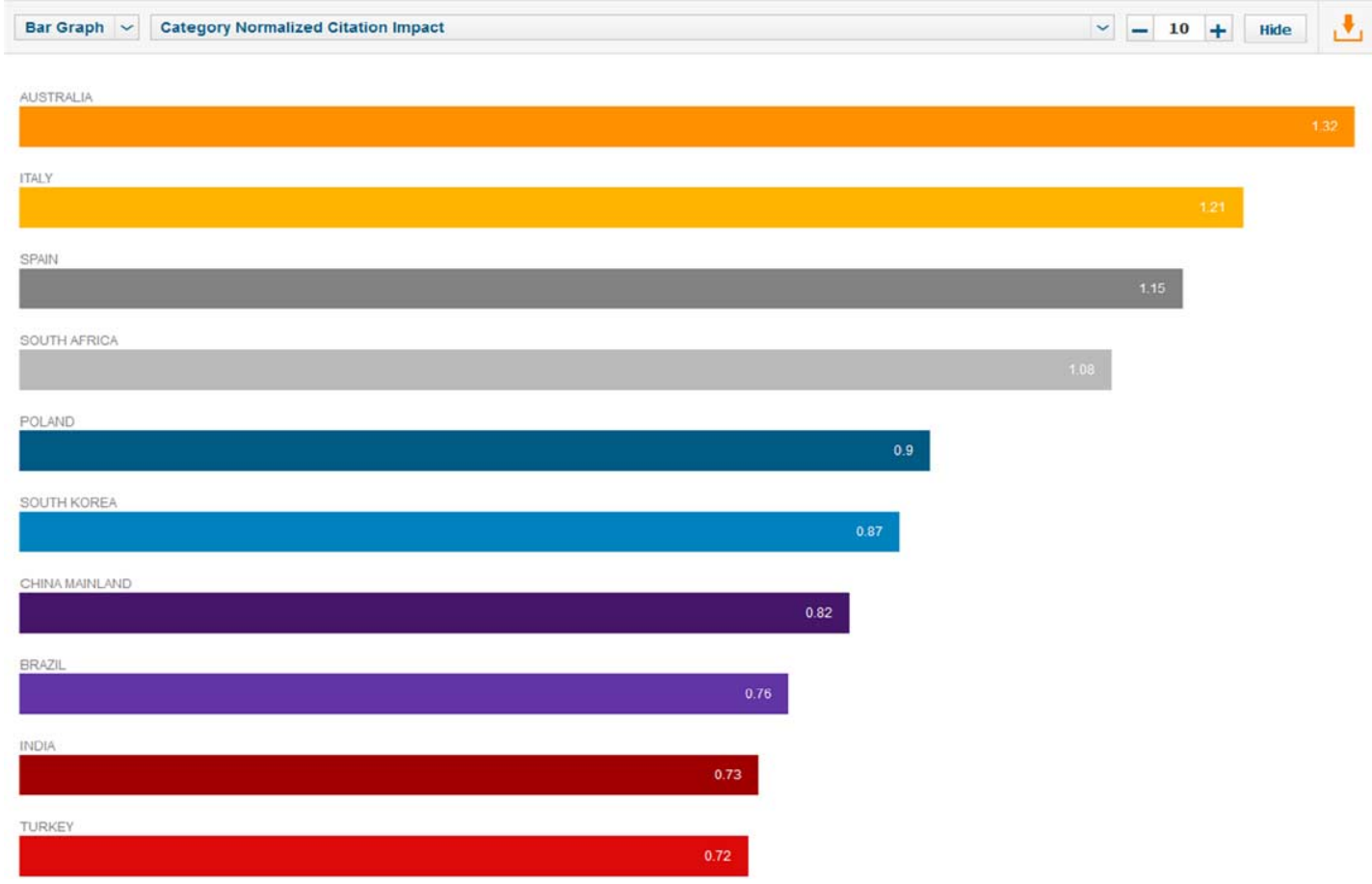

Fig. 5. Category normalized citation impact (Source: InCites) .

\begin{tabular}{|r|r|r|r|}
\multicolumn{5}{|c|}{ Rankings } \\
& Journals 2015 & $\frac{\text { Total Papers }}{\text { 2004-2015 }}$ & Impact \\
\hline 1 & PR China & PR China & Australia \\
\hline 2 & Italy & Italy & Italy \\
\hline 3 & Australia & Spain & Spain \\
\hline 4 & Spain & Australia & S. Africa \\
\hline 5 & Poland & India & Poland \\
\hline 6 & Brazil & S. Korea & S. Korea \\
\hline 7 & S. Korea & Brazil & PR China \\
\hline 8 & India & Turkey & Brazil \\
\hline 9 & Turkey & Poland & India \\
\hline 10 & S. Africa & S. Africa & Turkey \\
\hline & & & \\
\hline
\end{tabular}

Fig. 6. Country rankings.

But this is not the whole story. Serious side-effects have emerged from the globalization of scholarly communication. There is the practice of rewarding scholars disproportionately for publishing in highimpact journals. There is the willingness to abandon scientific integrity in exchange for the profit that comes from inflating the content of an open access journal with no regard for solid peer review.

I have witnessed such questionable editorial practices from not only Asian publishers, but also from some leading Western publishers. The first and most common practice is the attempt to artificially raise Citation Impact scores through intentionally-excessive self-citations or by groups of journals working together in deliberate and artificial citation stacking. Things do not go well for the misguided souls who 
engage in these sorts of activities. Their scams are easily detected and are often reported by concerned users.

More damaging than the reputation of one journal or group of journals, however, are the consequences to be borne by legitimate scholars the world over as science and the integrity of the scientific method become vulnerable to serious doubt. After all, our reliance on the integrity of the communication of scientific inquiry for the survival of mankind has never been greater.

In my years working with the publishing community and building Web of Science I have witnessed some incredible progress in the communication of scholarly results. I have also seen some unbelievably unethical behavior from individuals and organizations that try to appear as though they are legitimate members of the scholarly community in order to gain some professional or economic benefit.

To be fair I must repeat that not all of this unethical behavior has come from the Far East. It is to be found among European and Middle-Eastern publishers and among publishers from both North and South America.

At the same time, some very fine work is emerging from the Chinese Academy of Science as well as from the National Research Foundation of South Korea. We should not assume that integrity in scholarly publishing or the lack thereof is the sole province of one country or region even while some very easilyobserved abuses are apparent to all.

Given the tremendous pressure exerted upon researchers and scholars to publish results in order to gain or maintain position, secondary publishers need to demonstrate clearly and decisively that the tools we use to detect and remove questionable work from our products are sharp and at the ready.

\begin{abstract}
About the author
For more than thirty-three years, James Testa has built his career on establishing and maintaining relationships within the international STM and scholarly publishing community in building content for Web of Science, the world's oldest and largest index of bibliographic information citation index available in today's market.
\end{abstract}

